\title{
Dupuytren-Like Contracture of the Foot: Ledderhose Disease
}

\author{
Osman Akdag ${ }^{1}$ Gokce Yildiran ${ }^{1}$ Mehtap Karamese ${ }^{1}$ Zekeriya Tosun ${ }^{1}$ \\ ${ }^{1}$ Department of Plastic, Reconstructive, and Aesthetic Surgery, Selcuk \\ University Medical Faculty, Konya, Turkey \\ Address for correspondence Gokce Yildiran, MD, Department of \\ Plastic, Reconstructive, and Aesthetic Surgery, Selcuk University \\ Medical Faculty, Konya, Turkey (e-mail: ggokceunal@gmail.com).
}

Surg J 2016;2:e102-e104.

\author{
Abstract \\ Keywords \\ - Dupuytren \\ - foot \\ - Ledderhose disease \\ - plantar fibromatosis
}

Introduction Plantar fibromatosis is a rare hyperproliferative disease of plantar aponeurosis and is also called Ledderhose disease. Case properties and treatment are discussed in this report.

Case Report A 30-year-old man presented with painful bilateral plantar nodules. He had multiple and bilateral fixed and solid nodules on the plantar and medial side of his feet measuring $1 \mathrm{~cm}$ each. Ultrasound was performed and hypoechoic homogeneous nodules were detected. The patient underwent surgery, and the nodes were removed via a plantar incision with 2 -cm safety distance.

Discussion Ledderhose disease is a rare, hyperproliferative disorder of the plantar aponeurosis. The nodules are slow growing and found in the medial part of the plantar fascia. The precise etiology remains unknown. The treatment options are conservative management, steroid injections, radiotherapy, and surgery.

Conclusion The main cause of this disease remains uncertain. Related conditions should be evaluated, and a patient who presents with Dupuytren or Peyronie disease should also be investigated for Ledderhose disease.
Plantar fibromatosis, or Ledderhose disease, is a rare hyperproliferative disease of plantar aponeurosis. ${ }^{1}$ Georg Ledderhose described the disease in 1894 as a Dupuytrenlike disease of the foot. ${ }^{2}$ Nodules measuring 1 to $2 \mathrm{~cm}$ on the medial side of the foot arch are evidence for the disease. ${ }^{3}$ Treatment of this disease is discussed via one case of plantar fibromatosis.

\section{Case Report}

A 30-year-old man presented painful bilateral plantar nodules. Physical examination showed multiple and bilateral fixed and solid nodules measuring $1 \mathrm{~cm}$ each on the plantar and medial side of his feet ( - Fig. 1). Five years earlier, the first painless nodule appeared in his right foot, and the number of nodules increased and become painful over the following years. He had using orthopedic insoles for the last 6 months. He was not taking any medication, and there was no family history of those nodules. Routine laboratory tests and blood glucose levels were normal. He did not have Dupuytren disease, diabetes mellitus, alcohol addiction, penile fibromatosis, epilepsy, or frozen shoulder. Ultrasound was performed, and hypoechoic homogeneous nodules were detected. The patient underwent surgery, and the nodes were removed via a plantar incision with $2-\mathrm{cm}$ safety distance (-Fig. 2). There was no skin or muscle infiltration. The skin was closured primarily, wound dressing was changed once a day, and touching the ground was banned for 1 day. We continue to follow the patient ( - Fig. 3 ).

\section{Discussion}

Ledderhose disease is a rare, hyperproliferative disorder of the plantar aponeurosis. ${ }^{1,4}$ The nodules are slow growing and found in the medial part of the plantar fascia. This nodular tissue is progressive and replaces normal aponeurosis. ${ }^{2}$ The received

March 20, 2016

accepted after revision

August 9, 2016
DOI http://dx.doi.org/

10.1055/s-0036-1593355.

ISSN 2378-5128.
Copyright $\odot 2016$ by Thieme Medical

Publishers, Inc., 333 Seventh Avenue,

New York, NY 10001, USA.

Tel: +1(212) 584-4662.
License terms

(®) (1) $\Theta \circledast$ 


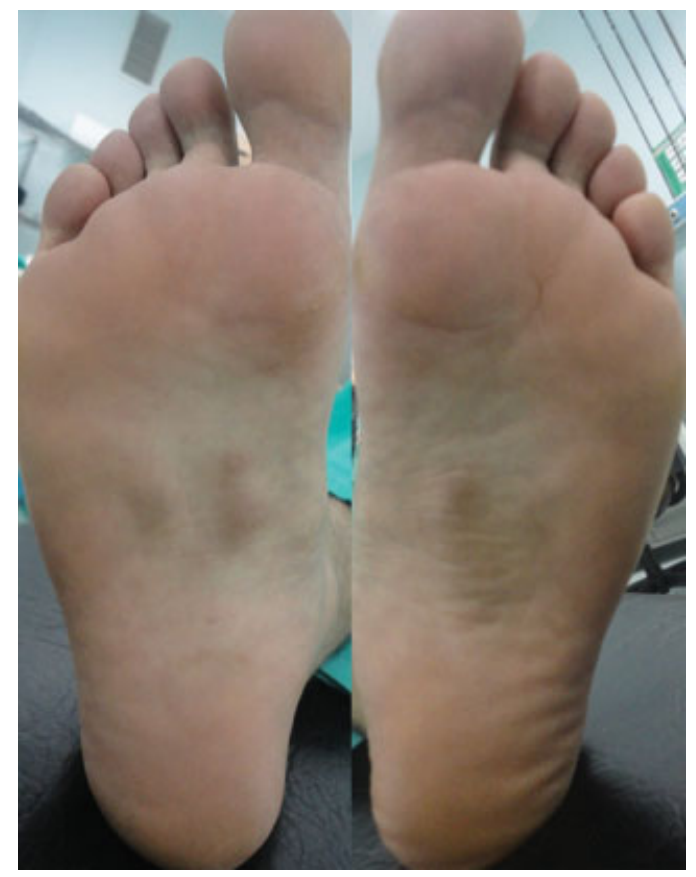

Fig. 1 Preoperative view of nodules of plantar fascia.

frequency of the disease was reported as $1.75 / 100,000$ by Pickren et al and $1 / 100,000$ by de Bree et al. ${ }^{5,6}$ The disease is concomitant with Dupuytren disease in 2 to $18 \%$ and with Peyronie disease in $4 \%$ of patients. ${ }^{7,8}$ Our patient had neither Dupuytren nor Peyronie disease. Males are affected more often than females, and symptoms usually start in the third to fourth decades. ${ }^{1}$ Our case was a 30 -year-old man. Ledderhose

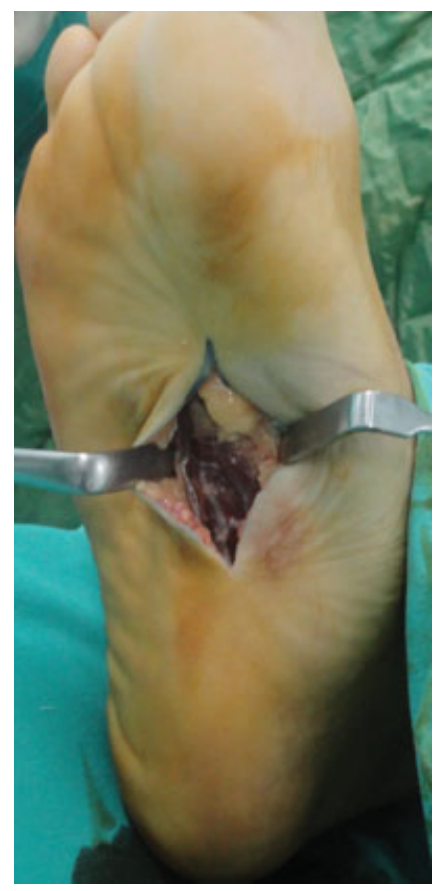

Fig. 2 Intraoperative view of nodule.

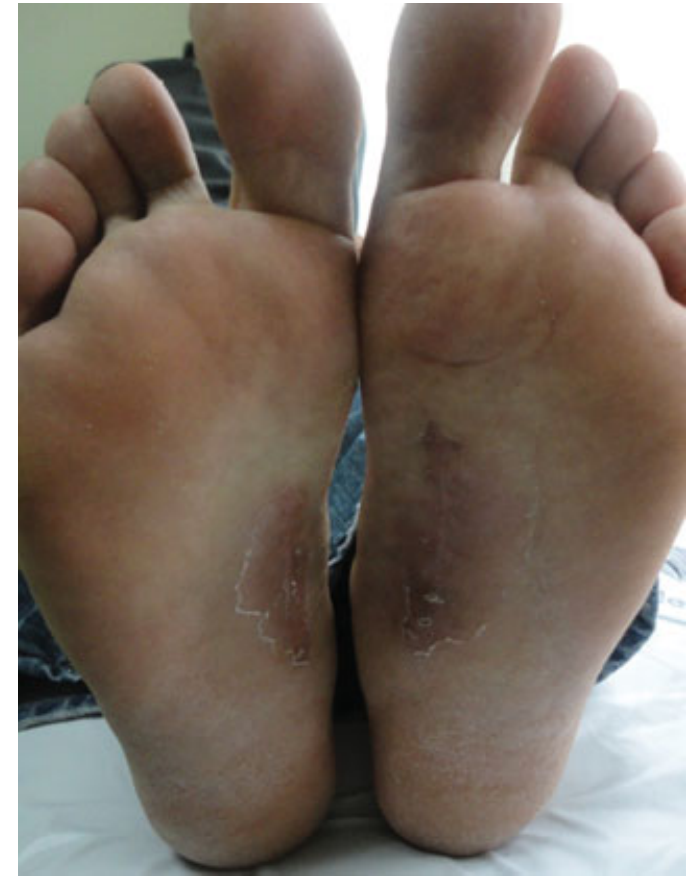

Fig. 3 View at postoperative 8 weeks.

disease exhibits bilateral affection in $25 \%$ of cases, as in our patient. $^{9}$

The precise etiology remains unknown ${ }^{1,2,10,11}$; however it is related with some conditions and diseases like Dupuytren disease, ${ }^{7}$ frozen shoulder, alcohol addiction, epilepsy, diabetes mellitus, and penile fibromatosis. ${ }^{10,11}$ In our case, none of these conditions existed and blood glucose levels were normal; the independence of our case from the known related conditions makes the case interesting.

The diagnosis of Ledderhose disease is usually clinical and does not frequently require confirmation. ${ }^{12}$ However, Omor et al reported that magnetic resonance imaging has an important role in diagnosis and evaluating the severity of disease. ${ }^{10}$ The differential diagnosis of plantar masses includes plantar fasciitis, leiomyoma, rhabdomyosarcoma, and liposarcoma. ${ }^{10}$ We performed ultrasound to confirm the clinical diagnosis. After excision, histopathologic analysis revealed fibromatosis.

The treatment options are conservative management, steroid injections, radiotherapy, and surgery. Conservative treatment and steroid injections are options for painless and early painful stages. ${ }^{11}$ However, the node's reduction or further relapses after healing are inevitable with only conservative therapies and without surgery. ${ }^{11,13-15}$

When conservative treatments fail to reduce the symptoms, surgery is indicated. ${ }^{11}$ Our patient used orthopedic insoles for the painful nodules for 6 months; however, because the symptoms were aggravated, surgical excision was indicated. Surgical excision is divided into three types: local, wide, and complete fasciectomy. ${ }^{11,16,17}$ Van der Veer et al reported that local resections relapse with a percentage of $100 \%$ and complete fasciectomy relapses $25 \%{ }^{18}$ Dürr et al reported that wide excision, with a safe distance of 2 to $3 \mathrm{~cm}$, 
may relapse with a percentage of $78 \%{ }^{19}$ Total removal of the plantar fascia results in extension of the foot longitudinal arch, so we performed a wide excision with a 2-cm margin.

\section{Conclusion}

Plantar fibromatosis is rare, benign, easy to diagnose, hyperproliferative disease. However, the main cause of this disease remains uncertain, and related conditions should be evaluated. A patient who presents with Dupuytren or Peyronie disease should be investigated for Ledderhose disease. Further investigations are needed for certain etiopathogenesis of this rare condition.

\section{References}

1 Heyd R, Dorn AP, Herkströter M, Rödel C, Müller-Schimpfle M, Fraunholz I. Radiation therapy for early stages of morbus Ledderhose. Strahlenther Onkol 2010;186(1):24-29

2 Fausto de Souza D, Micaelo L, Cuzzi T, Ramos-E-Silva M. Ledderhose disease: an unusual presentation. J Clin Aesthet Dermatol 2010;3(9):45-47

3 Knobloch K, Vogt PM. High-energy focussed extracorporeal shockwave therapy reduces pain in plantar fibromatosis (Ledderhose's disease). BMC Res Notes 2012;5:542

4 Motolese A, Mola F, Cherubino M, Giaccone M, Pellegatta I, Valdatta L. Squamous cell carcinoma and Ledderhose disease: a case report. Int J Low Extrem Wounds 2013;12(4):297-300

5 Pickren JW, Smith AG, Stevenson TW Jr, Stout AP. Fibromatosis of the plantar fascia. Cancer 1951;4(4):846-856

6 de Bree E, Zoetmulder FA, Keus RB, Peterse HL, van Coevorden F. Incidence and treatment of recurrent plantar fibromatosis by surgery and postoperative radiotherapy. Am J Surg 2004;187(1):33-38
7 Gudmundsson KG, Jónsson T, Arngrímsson R. Association of Morbus Ledderhose with Dupuytren's contracture. Foot Ankle Int 2013;34(6):841-845

8 Allen RA, Woolner LB, Ghormley RK. Soft-tissue tumors of the sole; with special reference to plantar fibromatosis. J Bone Joint Surg Am 1955;37-A(1):14-26

9 Classen DA, Hurst LN. Plantar fibromatosis and bilateral flexion contractures: a review of the literature. Ann Plast Surg 1992;28(5): 475-478

10 Omor Y, Dhaene B, Grijseels S, Alard S. Ledderhose disease: clinical, radiological (ultrasound and MRI), and anatomopathological findings. Case Rep Orthop 2015;2015:741461

11 Veith NT, Tschernig T, Histing T, Madry H. Plantar fibromatosistopical review. Foot Ankle Int 2013;34(12):1742-1746

12 Zgonis T, Jolly GP, Polyzois V, Kanuck DM, Stamatis ED. Plantar fibromatosis. Clin Podiatr Med Surg 2005;22(1):11-18

13 Meek RM, McLellan S, Reilly J, Crossan JF. The effect of steroids on Dupuytren's disease: role of programmed cell death. J Hand Surg [Br] 2002;27(3):270-273

14 Ketchum LD, Donahue TK. The injection of nodules of Dupuytren's disease with triamcinolone acetonide. J Hand Surg Am 2000; 25(6):1157-1162

15 Pentland AP, Anderson TF. Plantar fibromatosis responds to intralesional steroids. J Am Acad Dermatol 1985;12(1 Pt 2):212-214

16 Beckmann J, Kalteis T, Baer W, Grifka J, Lerch K. [Plantar fibromatosis: therapy by total plantarfasciectomy]. Zentralbl Chir 2004; 129(1):53-57

17 Griffith JF, Wong TY, Wong SM, Wong MW, Metreweli C. Sonography of plantar fibromatosis. AJR Am J Roentgenol 2002;179(5): 1167-1172

18 van der Veer WM, Hamburg SM, de Gast A, Niessen FB. Recurrence of plantar fibromatosis after plantar fasciectomy: single-center long-term results. Plast Reconstr Surg 2008;122(2):486-491

19 Dürr HR, Krödel A, Trouillier H, Lienemann A, Refior HJ. Fibromatosis of the plantar fascia: diagnosis and indications for surgical treatment. Foot Ankle Int 1999;20(1):13-17 